\title{
EFFECT OF INCREASED CROWN-IMPLANT RATIO ON THE STRAIN DEVELOPED AROUND SHORT DENTAL IMPLANTS (IN VITRO STUDY)
}

\author{
Ala'a M. Khalifa ${ }^{1} B D S$, Ahmed M. Abdelhamid ${ }^{2} P h D$, Mohammed S. Nassif ${ }^{3} P h D$, Sherif M. \\ Eldakkak $P h D$.
}

\begin{abstract}
INTRODUCTION:Implants in atrophic posterior regions of the jaw often require short dental implants leading to increased crownimplant ratio and mechanical stress. Short and small diameter dental implants have been associated with higher risk of biomechanical complications and implant failure. However the use of short implants has become increasingly common due to anatomic limitations and need to avoid surgical rehabilitation of the reduced ridge. .

OBJECTIVES: Evaluation of the effect of increased crown-implant ratio on the strain developed around short dental implants compared to conventional implants length.

MATERIALS AND METHODS: A bounded saddle replica was simulated using polyurethane test blocks where fourteen dental implants have been placed. Specimens were divided into two parallel groups $(n=7)$ according to implant length, Group (I) - implants of conventional length, Group (II) implants of short length. Strain gauges were connected to a strain meter to record the developed strain. A universal testing machine was used for load application up to $100 \mathrm{~N}$. The data were statistically analyzed $(\mathrm{p} \leq 0.05)$.

RESULTS: Group I exhibited the lower mean micro-strain values $(512.26 \pm 427.39 \mu \varepsilon)$ than Group II ( $804.05 \pm 487.37 \mu \varepsilon)$. There was no statistically significant difference between both groups $(\mathrm{p}>0.05)$. There was a statistical significance between oblique loads and vertical loads for each group.

CONCLUSIONS: Increasing the crown implant ratio had no significant effect on the strains developed around dental implants. KEYWORDS: Short Implants, Long Implants, Crown Implant Ratio, Strain gauge.

1- Instructor at Removable Prosthodontics Department, Faculty of Dentistry, Pharos University in Alexandria, Egypt.

2- Professor of Removable Prosthodontics, Prosthodontics Department, Faculty of Dentistry, Alexandria University, Egypt.

3- Associate Professor of Dental Biomaterials, Department of Dental Biomaterials, Faculty of Dentistry, Ain Shams University, Egypt.

4- Lecturer of Removable Prosthodontics, Prosthodontics Department, Faculty of Dentistry, Alexandria University, Egypt.
\end{abstract}

\section{Corresponding author:}

E-mail: alaa.maher.khalifa@gmail.com

\section{INTRODUCTION}

Short implants offer the possibility to avoid bone augmentation for the patients with advanced alveolar bone resorption, where the insertion of regular length dental implants $(>8 \mathrm{~mm})$ is problematic. In particular, in the posterior maxilla, where there is a risk of perforating the maxillary sinus during implant placement when alveolar bone is deficient.

Short implants in this region are an interesting alternative and a therapeutical option to vertical augmentation since the treatment is faster, cheaper, and associated with less morbidity (1).

Initially, the required implant length was typically considered to be between 10 and $13 \mathrm{~mm}$ to allow for adequate osseointegration of a sufficiently large area and for strength. This was also regarded as the suitable length that would respect anatomical structures in most patients.
Over time, alternative lengths and diameters were introduced in response to clinical demands: first, narrower and longer length implants, then shorter implants with wider diameters and later, shorter implants with a modified form. Macro-geometric design is a key factor, allowing implants to be both shorter and narrower (2).

Crown-root ratio has been a decisive factor in the selection of the abutments and prognosis of the prosthesis. Abutments with crown-root ratio lower than 1:1 was considered a hazard in relation to load applied. The position of the fulcrum differentiates between an anatomical crown-to-implant ratio and clinical crown-toimplant ratio; in the former the fulcrum is located at the implant shoulder, while in the latter the fulcrum is positioned at the bone crest. Nissan et al, in two in vitro studies, suggested that the use of crown height space is a more significant factor than the crown-to-implant ratio in 
assessing biomechanics-related detrimental effects on prosthetic complications. The crown height space is an anatomical parameter that is defined as the distance between the occlusal plane and the crestal bone. For each one mm increase in crown height space, the cervical load is increased by $20 \%$. Biomechanically, a crown height space value greater than $15 \mathrm{~mm}$ is regarded as unfavorable; Nissan et al explained the absence of significant correlation between the crown-to-implant ratio and crestal bone loss in previous clinical studies by the fact that the value of crown height space was below the detrimental limit of $15 \mathrm{~mm}$ (3).

Furthermore, the crown to root ratio is used as a prime indicator of the long-term prognosis of a given tooth. It extrapolates the biomechanical concept of a class I lever for evaluating abutment teeth with the fulcrum lying in the middle portion of the root residing in alveolar bone. As progressive bone loss occurs, the fulcrum moves apically, and as a result, the tooth is more susceptible to harmful lateral occlusal forces (4).

Strain gauge has been widely used to measure strain development around experimental objects. Strain gauge bonded to external tooth surfaces can be used to study stress in tooth-related areas. Several studies have been employed comparing finite element analysis and strain gauge measurement for the purpose of validation $(5,6)$.

\section{MATERIALS AND METHODS}

A bounded saddle replica was created to simulate a clinical scenario of a single tooth replacement for a missing maxillary left first premolar. The blocks used as an alternative test medium for human bone were Solid Rigid Polyurethane Test blocks (Aptic Medical, Washington, USA). The uniformity and consistent properties of rigid polyurethane foam for comparative testing are $5 \mathrm{~cm} \mathrm{x} 12.5 \mathrm{~cm} \mathrm{x} 4.5 \mathrm{~cm}$.

Fourteen customized blocks were obtained measuring $2 \mathrm{~cm}$ in length $5 \mathrm{~cm}$ in width and $4.5 \mathrm{~cm}$ in height, by sewing down the supplied blocks (7).

Scanning was done using 3D scanner (Copenhagen, Denmark) of a patient's diagnostic cast with a missing maxillary left first premolar, and an intact inter-abutment distance of the edentulous space of $8 \mathrm{~mm}$. The model was sectioned from the maxillary left canine to the maxillary left second premolar using special software Magics software (version 8, Leuven, Belgium).

The bounded saddle replica was created by printing out the final design using a special 3D Dental printer (EnvisionTEC, Germany) with specific material (EDenstone) that was fixed on the Polyurethane test blocks using Cyanoacrylate adhesive.

The bounded saddle replicas were scanned by Cone Beam Computed Tomography (CBCT) (J. Morita, California, USA) and with the use of a software program the surgical stent was printed out using the special 3D Printer, onto which a titanium sleeve was attached. One surgical guide was fabricated from a specific material (EShell ${ }^{\circledR}$ 600).
Study samples were randomly divided into two main groups seven blocks each according to the implant length. Group I (conventional implants): $12 \mathrm{~mm}$ dental implant length, and $4.1 \mathrm{~mm}$ implants diameter with microthreads design.

Group II (short implants): $7 \mathrm{~mm}$ dental implant length, and $5.5 \mathrm{~mm}$ implants diameter, and with microthreads design.

For both groups the surgical guide was placed onto the block (bounded saddle replica) and through the titanium sleeve; a hole was drilled for implant installation. For group I: 7 dental implants of $12 \mathrm{~mm}$ length were installed in their corresponding blocks and 7 Titanium straight abutments of $4.5 \mathrm{~mm}$ diameter were tightened with the corresponding abutment screws according to the manufacturer's instructions with a calibrated torque driver. For group II: 7 dental implants of $7 \mathrm{~mm}$ length were installed in their corresponding blocks and 7 Titanium straight abutments of $5.5 \mathrm{~mm}$ diameter were tightened with the corresponding abutment screws according to the manufacturer's instructions with a calibrated torque driver.

This author seems to have uploaded his/her entire $\mathrm{MD} / \mathrm{PhD}$ dissertation on to the system. He/she is advised to resubmit an abstract of the workTwo strain gauges (CC33, EP-34strain gauge) were fixed for each implant buccally and palatally on the model adjacent to the implant site. Strain gauges were bonded to the selected sites using Cyanoacrylate adhesive (Figure 1). Then were connected to a strain meter (Kyowa sensor interface PCD-300A, Kyowa Electronic Instrument Co. Japan) to record the developed strain. A Universal Testing Machine was used for load application at four points: the central fossa of the crown, the buccolingual midpoint of the mesial and distal marginal ridges and an oblique $\left(45^{\circ}\right.$ inclined) load at the central fossa.

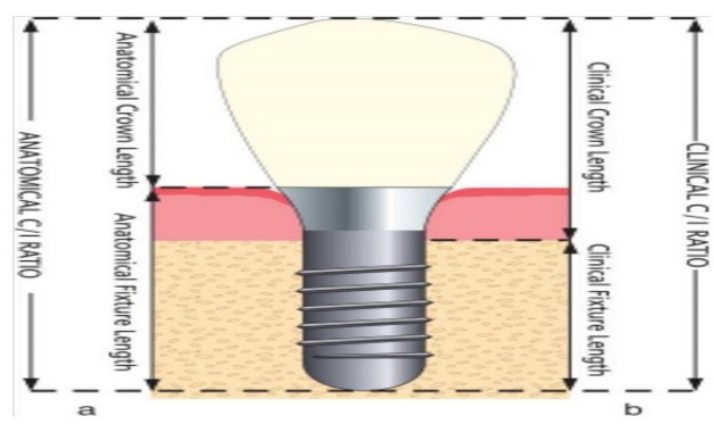

Figure (1): Showing occlusal view of bounded saddle replica with strain gauge wires attached buccally and palatally.

\section{Statistical analysis}

Data were fed to the computer and analyzed using IBM SPSS software package version 20.0. (Armonk, NY: IBM Corp). The Kolmogorov-Smirnov test was used to verify the normality of distribution. Quantitative data were described using range (minimum and maximum), mean, standard deviation and median. Significance of the obtained results was judged at the $5 \%$ level (8).

The statistical tests used to analyze the data obtained were: 


\section{1 - Mann Whitney test}

For abnormally quantitative variables, to compare between two studied groups.

\section{2 -Wilcoxon signed ranks test}

For abnormally quantitative variables, to compare between two studied groups.

\section{RESULTS}

By using Mann Whitney test and Wilcoxon signed ranks test for statistical analysis of micro-strain values of different loading sites within Group I and Group II.

A comparison was done with the sum of microstrains recorded from both buccal and palatal surfaces as a result of the application of both types of loads the vertical and the oblique (Table 1).

Table 1: Mean values of the sum of microstrains $(\mu \varepsilon)$ at the buccal and palatal surfaces of the implants resulting from forces applied at two different angulations (vertical and oblique)

\begin{tabular}{|l|c|c|c|c||}
\hline $\begin{array}{c}\text { Over All } \\
\text { (Buccal + Palatal) }\end{array}$ & $\begin{array}{c}\text { Group I } \\
\text { (n= 7) }\end{array}$ & $\begin{array}{c}\text { Group } \\
\text { II } \\
(\mathbf{n}=7)\end{array}$ & U & P \\
\hline Vertical & $90.83-$ & $198.33-$ & & \\
Min. - Max. & 1396.67 & 1645.83 & & \\
& $512.26 \pm$ & $804.05 \pm$ & 15.0 & 0.225 \\
Mean \pm SD. & 427.39 & 487.37 & & \\
Median & 399.17 & 860.0 & & \\
\hline Oblique & $1997.50-$ & $3172.50-$ & & \\
Min. - Max. & 5247.50 & 5995.0 & & \\
Mean \pm SD. & $3709.29 \pm$ & $4757.14 \pm$ & 10.0 & 0.064 \\
Median & 1181.65 & 1183.43 & & \\
\hline \multicolumn{1}{|c|}{ P } & 3482.50 & 4305.0 & & \\
\hline
\end{tabular}

U, p1: U and p values for Mann Whitney test for comparing between the two groups

$\mathrm{Z}$, $\mathrm{p}_{2}$ : $\mathrm{Z}$ and $\mathrm{p}$ values for Wilcoxon signed ranks test for comparing between the two groups

*: Statistically significant at $\mathrm{p} \leq 0.05$

When comparing between the two studied groups, Group II displayed higher mean microstrain values due to vertical loading than did Group I, but the values remain statistically insignificant. The same pattern was seen for the oblique loads, Group II still showed higher mean microstrain values when compared to Group I.

However, when comparing between the two types of loads, the microstrains developed due to the vertical and the oblique loading in each group individually, In Group I the microstrain recorded from the oblique loads are outstandingly higher than the values from the vertical loads revealing a statistical significance where $\mathrm{P}$ value was 0.018 .

For Group II once again the microstrains recorded from the oblique loading are remarkably greater than the values from the vertical loading. Therefore, oblique loading revealed a statistically significant effect on the microstrain values with a $\mathrm{P}$ value of 0.028 (Figure 2 ).

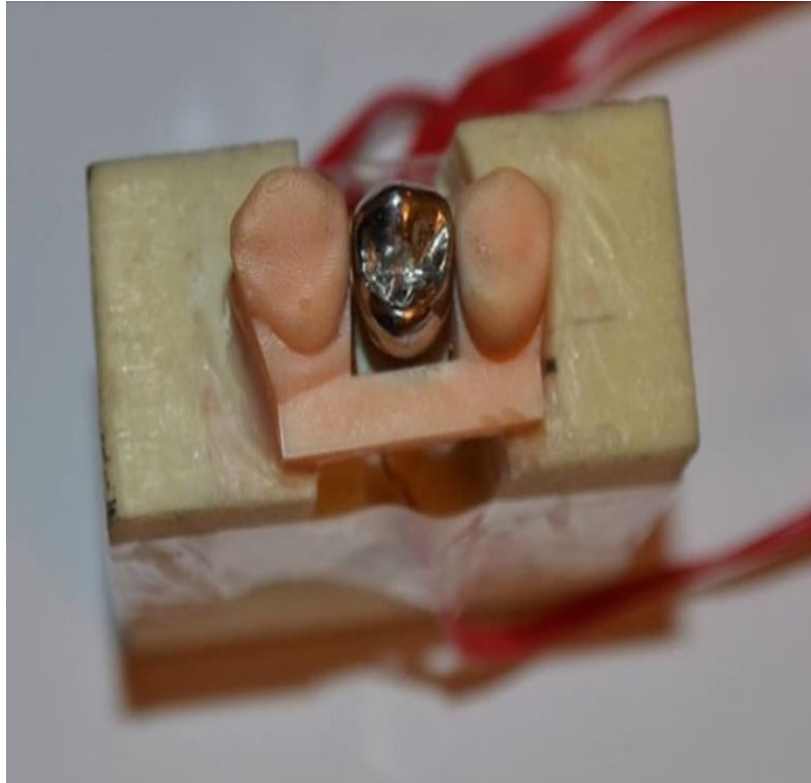

Figure (2): Comparison of total micro-strain values of both buccal and palatal aspects for both study groups under the two types of loads (vertical and oblique).

As for the oblique load, (Table 2) with regards to the buccal and palatal surface readings, Group II showed higher values than Group I but the difference was statistically insignificant. As for both Groups I and II, the mean microstrain values recorded from the buccal surfaces were remarkably greater than the values from the palatal surfaces, revealing a statistical in both groups with $P$ value $\leq 0.05$.

Figure 3 shows the average of microstrains resultant from oblique loads when recorded from both the buccal and palatal surfaces of the implants for both the studied groups.

\section{DISCUSSION}

The present study was conducted to evaluate the influence of increased crown to implant ratio on the strain developed around short dental implants for the single tooth replacement of a maxillary left first premolar.

Surgical guide was manufactured with the aid of CBCT to estimate the orientation and location of the implant to be inserted before implant placement. CBCT has been regarded as a high-quality reliable image acquisition method for the dento-maxillomandibular area, in comparison with other tomographic methods (9).

Table 2: Mean values of microstrains $(\mu \varepsilon)$ at the buccal and palatal surfaces of the implants resulting from oblique $\left(45^{\circ}\right)$ forces 


\begin{tabular}{|c|c|c|c|c|}
\hline Oblique & $\begin{array}{c}\text { Group I } \\
(n=7)\end{array}$ & $\begin{array}{c}\text { Group II } \\
(\mathbf{n}=7)\end{array}$ & $\mathbf{U}$ & $\mathbf{p}$ \\
\hline $\begin{array}{l}\text { Buccal } \\
\text { Min. - Max. } \\
\text { Mean } \pm \text { SD. } \\
\text { Median } \\
\end{array}$ & $\begin{array}{l}3840.0-10240.0 \\
6631.4 \pm 2107.8 \\
6435.0\end{array}$ & $\begin{array}{l}4295.0-10240.0 \\
7979.3 \pm 2322.4 \\
7210.0\end{array}$ & 14.50 & 0.196 \\
\hline $\begin{array}{l}\text { Palatal } \\
\text { Min. - Max. } \\
\text { Mean } \pm \text { SD. } \\
\text { Median } \\
\end{array}$ & $\begin{array}{c}155.0-2160.0 \\
787.14 \pm 662.78 \\
780.0 \\
\end{array}$ & $\begin{array}{c}520.0-2050.0 \\
1535.0 \pm 486.49 \\
1660.0 \\
\end{array}$ & 11.0 & 0.084 \\
\hline $\mathbf{P}$ & $0.018^{*}$ & $0.018^{*}$ & & \\
\hline
\end{tabular}

significance in both groups with $\mathrm{P}$ value $\leq 0.05$.

$\mathrm{U}, \mathrm{p} 1$ : $\mathrm{U}$ and $\mathrm{p}$ values for Mann Whitney test for comparing between the two groups

$\mathrm{Z}$, p2: $\mathrm{Z}$ and $\mathrm{p}$ values for Wilcoxon signed ranks test for comparing between the two groups

*: Statistically significant at $p \leq 0.05$

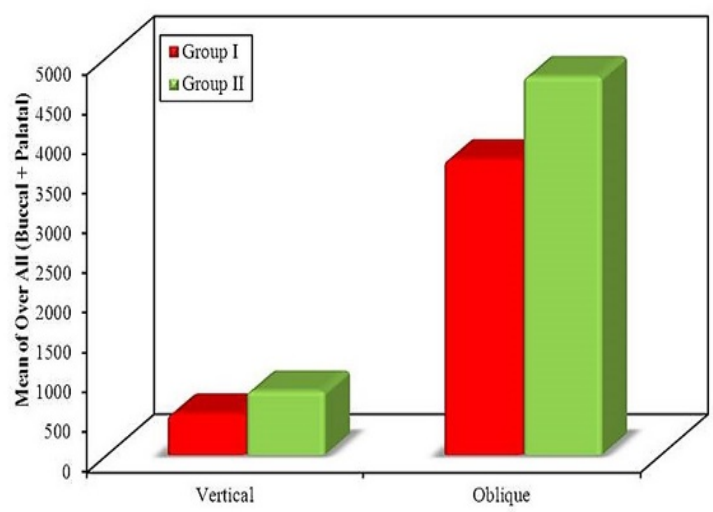

Figure (3): Comparison of total micro-strain values of oblique loads at the buccal and palatal surfaces for both study groups

The CAD/CAM Surgical guide template was used to insure that all the implants are placed precisely in their accurate positions for all the study samples. CAD/CAM technology facilitates accurate implant placement with less chances of error and it also offers reproducibility and hence minimizes the presence of variables during implant installation (10). A clear acrylic guide was fabricated, the transparency of the material allows inspection through the model to ensure proper implant placement within its proper place (11).

In order to standardize the entire superstructure of the two types of implants, the wax pattern crowns were fabricated using CAD-CAM system (12).

The flat surface of the polyurethane test blocks allowed the easy positioning and bonding of the strain gauges. Strain gauges were adhered to the two surfaces around the implant to monitor the stress when applying the loads; this method was followed by Nissan et al. (3) and Nishioka et al. (13).

Digital loading device was used to deliver loads in this study. It offered high accuracy position measurement, rapid data acquisition and full personal computer integration (14).

Loading was simulated by applying both an occlusal vertical load of $100 \mathrm{~N}$ to the most coronal part of the crown through the long axis of the restoration and implant and also an oblique load (inclined at $45^{\circ}$ ). The selection of the force amount and direction was utilized by several previous studies $(3,15)$.

In this study, loads were applied with vertical angulations parallel to the long axis of the implant (the central fossa, buccolingual midpoint of the mesial marginal ridge and buccolingual midpoint of the distal marginal ridge) then oblique ( $45^{\circ}$ inclined load) at the central fossa. This method was adopted by previous studies who found that strains from oblique forces are important to record $(3,16)$.

In the present study the crown height was maintained (8mm) but two different implant lengths were used; standard length implants $(12 \mathrm{~mm})$ and short length implants ( $7 \mathrm{~mm})$.

Several studies have revealed that, the greater the crown height in relevance to the implant length, the greater the moment of force or lever arm with any lateral force $(17,18)$. Forces may increase by $20 \%$ for every $1 \mathrm{~mm}$ of increase in crown height. Therefore, an increased crown-to-implant ratio will introduce significant moment arms on the implant and surrounding crestal bone when the implant restoration is subjected to lateral forces. It has been proposed that such moment loads would induce micro-rotations and stress concentration at the crest of the alveolar ridge at the implant-to-tissue interface and lead to crestal bone loss $(19,20)$.

Occlusal factors become important in posterior regions with high crown-to-implant ratio. Unfavorable crown implant ratio may result in excessive off-axis load that will increase the tendency to load the prosthetic stack and cervical supporting bone. This form of non-axial load creates moments of force with high stress concentrations at cervical bone crest and facial bone contours (21). Increasing the crown length and degree of non-axial load increases the risk of excessive occlusal overload due to an increased moment arm (22).

In this particular study the overall strains developed around the short implants were higher than those developed around the long implants when vertical loads were applied and these differences in the strains were found to be statistically insignificant. Also in case of oblique ( $45^{\circ}$ inclination) load application, the strains were higher around short implants than those developed around long implants and differences in the strains were not statistically significant.

A shorter implant has a greater crown implant ratio when compared to a longer implant with a constant crown height. Therefore, complications should be presumably anticipated in short implants. However, previous research has shown that short implants are clinically successful regardless of the crown implant ratio (23). In an investigation of 326 implants with a mean crown implant ratio of 1.6, Urdaneta et al observed that excessive crown implant ratio had no negative effect on the peri-implant bone loss but caused more significant prosthetic complications, such as screw loosening and porcelain 
fracture (7). These findings are compatible with the results of the current study which showed no statistical significance between short and dental implants regarding strain values from vertical or oblique loads.

On the contrary, the results of this study are in opposition to Chung et al. who claim that shorter and wider implants are associated with more bone loss and lower survival rates due to higher induced stresses (24). Another finite element study concluded that increasing the crown implant ratio could be destructive to the stress distribution on the implant system, especially under oblique loading (25). A study by Herrmann et al. showed that short implants failed more often than longer implants (26).

On the other hand, under oblique loading, the higher microstrain values were recorded buccally revealing a statistical significance. This is due to the crowns orientation on the self developed jig where the crown was tilted buccally. Therefore, higher forces were concentrated on the buccal cusp and higher readings were observed in the strain meter. Similar studies by Verri et al. and Nissan et al. also showed that the strain intensity at the buccal regions under oblique loading was statistically significant compared to other regions in all models $(\mathrm{p} \leq 0.005)(27,3)$.

These findings were in accordance with other studies, which stated that oblique load is associated with higher stresses $(28,29)$. It is important to emphasize that oblique load application has been related to more realistic occlusal loading (30). When comparing different loads application (vertical and oblique), it was possible to see some peculiarities in the stress distribution in different parts of the single implant system. The oblique load led to higher stress concentration in all parts analyzed (buccal, lingual).

No statistical significance was found when comparing short implants to longer implants under neither vertical nor oblique loads. This suggests that short implants can be a predictable and successful treatment option especially in cases where ridge resoprtion has occurred and limited amount of bone is available hindering the use of standard implant length.

These findings are in acceptance with several previous studies by Gentile et al. and Rokni et al. and more recent studies by Hentschel et al, Lemos et al, Fan $\mathrm{T}$ et al. The authors reported no difference in the short implant survival rate when compared to implants of greater length. An assumption could be made that the shorter implants have a larger crown-to-implant ratio than implants of greater length, yet there is no difference in their survival rate (31-35). This may indicate that the crown-to-implant ratio is not a good predictor of implant survival and as suggested by Schulte et al. the fact that the $\mathrm{C} / \mathrm{I}$ ratio has a role in the potential failure of implant restoration is questionable (36). Conversely these results yield contradiction to other studies by Hermann et al, Blanes et al, Staffrod et al. whom suggested that shorter implants are associated with lower survival rates and higher risks $(37,38,47)$.

The differences in the results reported in the literature might be rooted in the use of various methods; different implant brands with different geometries, shapes, and angles of stiffness, various angles of load exertion or confounding factors present in the clinical studies. This study was also limited by the fact that it is an in vitro study and should be confirmed with clinical studies (39).

\section{CONCLUSION}

Within the limitation of this study the following could be concluded:

1. Both implant lengths were associated with increased microstrain values when the load was applied obliquely than when the load was applied vertically.

2. The amount of microstrain was greater on the buccal side than on the palatal side when oblique loads were applied.

3. The length of the implant had no significant effect on the microstrains resulting from different directions of load where the crown height space is constant.

\section{CONFLICT OF INTREST}

The authors declare that they have no conflicts of interest.

\section{ACKNOWLEDGMENT}

I would like to acknowledge Marwan Aggag, for the exceptional support throughout the thesis process.

\section{REFERENCES}

1-Esposito M, Cannizarro G, Soardi E, Pellegrino G, Pistilli R, Felice P. A 3-year post-loading report of a randomized controlled trial on the rehabilitation of posterior atrophic mandibles: Short implants or longer implants in vertically augmented bone? Eur J Oral Implantol. 2011;4:301-11.

2-Buser D, Mericske-Stern R, Bernard JP, Behneke A, Behneke N, Hirt HP, et al. Long-term evaluation of non-submerged ITI implants. Part 1:8-year life table analysis of a prospective multi-center study with 2359 implants. Clin Oral Implants Res. 1997;8:161-72.

3-Nissan J, Ghelfan O, Gross O, Priel I, Gross M, Chaushu G. The effect of crown/implant ratio and crown height space on stress distribution in unsplinted implant supporting restorations. J Oral Maxillafac Surg. 2011;69:2990-4.

4-Rossi F, Botticelli D, Cesaretti G, De Santis E, Storelli $\mathrm{S}$, Lang NP. Use of short implants $(6 \mathrm{~mm})$ in a singletooth replacement: a 5-year follow-up prospective randomized controlled multicenter clinical study. Clin Oral Implants Res. 2016;27:458-64.

5-Bulqai H, Mashhadi M, Safari H, Samandari M, Geramipanah F. Effect of increased crown height on stress distribution in short dental implant components and their surrounding bone: A finite element analysis. J Prosthet Dent. 2015;113:548-57. 
6-Urdaneta RA, Rodriguez S, McNeil DC, Weed M, Chuang SK. The effect of increased crown-implant ratio on single tooth locking-taper implants. Int J Oral Maxillofac Implants. 2010;25:729-43

7-Huang H-L, Chang Y-Y, Lin D-J, Li Y-F, Chen K-T, Hsu J-T. Initial stability and bone strain evaluation of the immediately loaded dental implant: an in vitro model study. Clin Oral Implants Res. 2011;22:691-8.

8-Kirkpatrick LA, Feeney BC. A simple guide to IBM SPSS statistics for version 20.0. Student ed. Belmont, Calif.: Wadsworth, Cengage Learning; 2013.

9-Kassebaum DK, Nummikoski PV, Triplett RG, Langlais RP. Cross-sectional radiography for implant site assessment. Oral Surg Oral Med Oral Pathol. 1990;70:674-8.

10-Kola MZ, Shah AH, Khalil HS, Rabah AM, Harby NM, Sabra SA, et al. Surgical templates for dental implant positioning; current knowledge and clinical perspectives. Niger J Surg. 2015;21:1-5.

11-Vogel RC. Implant overdentures: a new standard care edentulous patients current concepts techniques. Compend Contin Educ Dent. 2008;29:270-6.

12-Persson AS, Andersson M, Odén A, SandborghEnglund G. Computer aided analysis of digitized dental stone replicas by dental CAD/CAM technology. Dent Mater. 2008;24:1123-30.

13-Nishioka RS, Rodrigues VA, De Santis LR, De MeloNishioka GN, Miyazaki Santos VM, Ávila Souza F. Comparative microstrain study of internal hexagon and plateau design of short implants under vertical loading. Implant Dent. 2016;25:135-9.

14-Hegazy SA, Elshahawi IM, Elmotayam H. Stresses induced by mesially and distally placed implants to retain a mandibular distal-extension removable partial overdenture: a comparative study. Int $\mathrm{J}$ Oral Maxillofac Implants. 2013;28:403-7.

15-de Faria Almeida DA, Pellizzer EP, Verri FR, Santiago JF Jr, de Carvalho PS. Influence of tapered and external hexagon connections on bone stresses around tilted dental implants: three-dimensional finite element method with statistical analysis. J Periodontol. 2014;85:261-9.

16-Lin C-L, Kuo Y-C, Lin T-S. Effects of dental implant length and bone quality on biomechanical responses in bone around implants: a 3-d non-linear finite element analysis. Biomed Eng Appl Basis Commun. 2005;17:44-9.

17-Misch CE, Bidez MW. Scientific rationale for dental implant design. In: Misch CE (ed). Contemporary implant dentistry. $3^{\text {rd }}$ ed. St. Louis: Mosby; 2008:20225.

18-Bidez MW, Misch CE. Force transfers in implant dentistry. Basic concepts and principles. Oral Implantol. 1992;18:264-74.

19-Misch CE. Dental evaluation: Factors of stress. In: Misch CE (ed). Contemporary implant dentistry. $2^{\text {nd }}$ ed. St. Louis: Mosby; 1999:123-9.
20-Bidez MW, Misch CE. Issues in bone mechanics related to oral implants. Implant Dent. 1992;1:289-94.

21-Weinberg LA. Reduction of implant loading using a modified centric occlusal anatomy. Int J Prosthodont. 1998;11:55-69.

22-Richter EJ. In vivo horizontal bending moments on implants. Int J Oral Maxillofac Implants. 1998;13:232-44.

23-Tawil G, Aboujaoude N, Younan R. Influence of prosthetic parameters on the survival and complication rates of short implants. Int J Oral Maxillofac Implants. 2006;21:275-82.

24-Chung SH, Heo SJ, Koak JY, Kim SK, Lee JB, Han JS, et al. Effects of implant geometry and surface treatment on osseointegration after functional loading: a dog study. J Oral Rehabil. 2008;35:229-36.

25-Moraes SL, Pellizzer EP, Verri FR, Santiago JF Jr, Silva JV. Three-dimensional finite element analysis of stress distribution in retention screws of different crown-implant ratios. Comput Methods Biomech Biomed Engin. 2015;18:689-96.

26-Herrmann I, Lekholm U, Holm S, Kultje C. Evaluation of patient and implant characteristics as potential prognostic factors for oral implantfailures. Int J Oral Maxillofac Implants. 2005;20:220-30.

27-Verri FR, Batista VE, Santiago JF Jr, Almeida DA, Pellizzer EP. Effect of crown-to-implant ratio on periimplant stress: A finite element analysis. Mater Sci Eng C Mater Biol Appl. 2014;45:234-40.

28-Iplikçioğlu H, Akça K, Cehreli MC, Sahin S. Comparison of non-linear finite element stress analysis with in vitro strain gauge measurements on a morse taper implant. Int J Oral Maxillofac Implants. 2003;18:258-65.

29-Nagasawa S, Hayano K, Niino T, Yamakura K, Yoshida T, Mizoguchi T, et al. Nonlinear stress analysis of titanium implants by finite element method. Dent Mater J. 2008;27:633-9.

30-Pesqueira AA, Goiato MC, Filho HG, Monteiro DR, Santos DM, Haddad MF, et al. Use of stress analysis methods to evaluate the biomechanics of oral rehabilitation with implants. J Oral Implantol. 2014;40:217-28.

31-Gentile MA, Chuang SK, Dodson TB. Survival estimates and risk factors for failure with $6 \times 5.7-\mathrm{mm}$ implants. Int $\mathrm{J}$ Oral Maxillofac Implants. 2005;20:930-7.

32-Rokni S, Todescan R, Watson P, Pharoah M, Adegbembo AO, Deporter D. An assessment of crown-to-root ratios with sintered porous-surfaced implants supporting prostheses in partially edentulous patients. Int J Oral Maxillofac Implants. 2005;20:6976.

33-Hentschel A, Herrmann J, Glauche I, Vollmer A, Schlegel KA, Lutz R. Survival and patient satisfaction of short implants during the first 2 years of function: a retrospective cohort study with 694 
implants in 416 patients. Clin Oral Implants Res. 2016;27:591-6.

34-Lemos CA, Ferro-Alves ML, Okamoto R, Mendonça MR, Pellizzer EP. Short dental implants versus standard dental implants placed in the posterior jaws: A systematic review and meta-analysis. J Dent. 2016;47:8-17.

35-Fan T, Li Y, Deng WW, Wu T, Zhang W. Short Implants (5 to $8 \quad \mathrm{~mm}$ ) Versus Longer Implants $(>8 \mathrm{~mm})$ with Sinus Lifting in Atrophic Posterior Maxilla: A Meta-Analysis of RCTs. Clin Implant Dent Relat Res. 2016; 19:207-15.

36-Schulte J, Flores AM, Weed M. Crown-to-implant ratios of single tooth implant-supported restorations. J Prosthet Dent. 2007;98:1-5.

37-Blanes RJ, Bernard JP, Blanes ZM, Belser UC. A 10year prospective study of ITI dental implants placed in the posterior region. II: Influence of the crown-toimplant ratio and different prosthetic treatment modalities on crestal bone loss. Clin Oral Implants Res. 2007;18:707-14.

38-Stafford GL. Short implants had lower survival rates in posterior jaws compared to standard implants. Evid Based Dent. 2016;17:115-6.

39-Bulaqi HA, Mousavi Mashhadi M, Safari $H$, Samandari MM, Geramipanah F. Effect of increased crown height on stress distribution in short dental implant components and their surrounding bone: A finite element analysis. J Prosthet Dent. 2015;113:54857. 